\title{
Physical Exercise for Life-Long Health
}

\section{Trevor Archer* and Max Rapp-Ricciardi}

Department of Psychology, University of Gothenburg, Sweden

\section{Introduction}

Physical activity/exercise as a general health requirement to ensure normal, healthy development of structure and function in children and adolescents as well as over the lifecycle remains an essential ingredient, as evidenced from global Public Health physical activity guidelines Hitchins et al. [1]; Lauer et al. [2], not least due to prevailing concerns regarding body mass in the younger, middle-aged and aged individuals Duberg et al. [3]; Schmidt et al. [4]; Sylvester et al. [5]. Physical exercise paradigms imply remarkably complex biological reciprocal interactions, invoking polygenic intercommunication within cells, tissues/organs, systems, with conspicuous cross-talk occurring among the elements of cardiovascular fitness and different expressions of health and wellbeing Ruegsegger et al. [6]. Increasingly, health clubs and institutions that cater for variants upon endurance and resistance training programs utilize appropriate conditioning-design and supervisory measures to describe: (i) moderate-intensity aerobic activity, (ii) vigorous-intensity aerobic activity, (iii) muscle-strengthening activity, and (iv) bonestrengthening activity that ensure safety and prospects for compliance. These programs have been planned carefully to promote muscular strength and limb-power, to ameliorate cardiovascular risk profiles, develop motor skills and performance, to offer a superior resilience to sports injuries, advance psychological well-being and provide self-fulfillment, and optimize cognitive functioning Hattar et al. [7]; Langguth et al. [8]; Ross et al. [9]. Exercise promotes healthy brain condition by reducing inflammation, suppressing oxidative stress and stabilizing physiological homeostasis Luongo et al. [10]; Mann et al. [11]; St Clair Gibson et al. [12].

Over the age spectrum of children, adolescents, middle-aged and elderly, physical exercise is associated with improved self-esteem and self-concept, as well as ameliorating emotional distress and anxietydepressive symptoms and biomarkers, with lack of exercise leading to ill-being and disaffect Aidar et al. [13]; Holmquist et al. [14]; Pelletier et al. [15] ; Sui et al. [16]. Generally, mood improvements are related to alleviation in cognitive flexibility, academic performance and environmentally-adapted behaviors: for example both acute and chronic exercise promoted executive functioning Dunsky et al. [17]; Ji et al. [18]; Northey et al. [19]. In a greater likelihood, a critical aspect pertaining to the cultivation of the exercise habit strength and accompanying life-style that is consolidated during childhood and adolescence confirms that these behavioral attributes persist into later adulthood, middle-aged and beyond Engberg et al. [20]; Mastrorilli et al. [21]. The variations between exercise behavior, hunger and appetite, dietary conditions and acylated ghrelin concentrations in venous blood seem enormous even in populations restricted to young, healthy male volunteers King et al. [22]. Hypertension patients presenting poor self-care as a consequence of low levels of self-efficacy/self-esteem, which was exemplified by the lifestyle of not implementing the necessary benefits of regular physical exercise, the negligence of which evoked the incapacity to controlled blood pressure and cardiovascular complications from hyper-elevated levels Magobe et al. [23]. Physical exercise provokes and instigates a plethora of neurobiological adaptive processes that inveigle adaptive cellular-tissue stress-response signaling pathways in the nervous system by involving neurotrophic factors, protein chaperones, these entities prevent both newly synthesized polypeptide chains and assembled subunits from aggregating into nonfunctional structures, DNA-repair proteins, autophagy and mitochondrial biogenesis Cobley et al. [24]; Liao et al. [25]; Theisen et al. [26].

The adaptations induced by physical exercise at the genetic, metabolic and neuromuscular levels augment the oxidative capacity derived from aerobic training, as well as inducing aspects of neuromuscular 're-modelling' as a consequence of moderate-intense resistance training Zanuso et al. [27], thereby providing an important interventional strategy for individuals diagnosed with type II diabetes; primarily, both exercise regimes ameliorate insulin sensitivity and diminish cardiovascular risk factors. These modifications create optimal conditions for substrate delivery, mitochondrial respiratory capacity and contractile function during exercise. Brown et al. [28] have indicated the existence of a relationship between self-reported exercise levels and brain amyloid in autosomal dominant AD mutation carriers whereby low exercise participants presented higher mean levels of brain amyloid than high exercise and expected symptom onset was a significant predictor of brain amyloid levels. In male C57BL/6J mice fed a high-fat diet continuously, wheel-running by itself induced remedial effects upon insulin concentrations but the running-wheel exercise did not did not alter insulin among mice fed with the regular chow replacement diet or among the control mice [1]. Nevertheless, an improvement in dietary conditions was found to enhance quality of health and induced the suppression of type II diabetes-like symptoms in addition to related conditions to a greater extent than simply exercise running, by itself. In a study involving eighty-five meta-analyses covering twenty-two chronic disease over a wide range, it was shown that the exercise interventions employed gave significant positive modifications of functional capacity of patients groups in 126 of the 146 (86\%) cases in comparison with the control group Pasanen et al. [29].

Telomere length has been associated with the aging process with particular relation to adverse, 'wear-and-tear' environments and conditions of poor health Chatterjee [30]; Mons et al. [31]; Solomon et al. [32]. It is becoming an increasingly consensus that telomere length of leukocytes and skeletal muscle cells may be positively associated with healthy living and inversely correlated with the risk of several agerelated diseases, including cancer conditions, chronic cardiovascular disorders, obesity, diabetes, chronic pain, and stress. Tucker [12] has studied aspects of aging with regard to leukocyte telomere length in a large random sample of adults in the United States. It was shown that adults who expressed high levels of exercise/activity were estimated to

${ }^{*}$ Corresponding author: Archer T, Department of Psychology, University of Gothenburg, Gothenburg, Sweden, Tel: +46 31 7864694; E-mail: trevor.archer@ psy.gu.se

Received: May 19, 2017; Accepted: May 22, 2017; Published: May 30, 2017

Citation: Archer T, Rapp-Ricciardi M (2017) Physical Exercise for Life-Long Health. Clin Exp Psychol 3: 150. doi: 10.4172/2471-2701.1000150

Copyright: (C) 2017 Archer T, et al. This is an open-access article distributed under the terms of the Creative Commons Attribution License, which permits unrestricted use, distribution, and reproduction in any medium, provided the original author and source are credited. 
possess a biologic aging advantage of nine years (140 base pairs $\div 15.6)$ over those adults who were sedentary; furthermore, the difference in cellular aging between participants describing high versus low exercise-activity was significant also, by 8.8 years, concomitant with the difference between those expressing high and moderate exerciseactivity (7.1 years). Taken together, exercise-activity was markedly and substantially associated with telomere length in these men and women. A strong case made be made for the notion that adults, of a spectrum of age-groups, who take part in high levels of exercise-activity possess the propensity to show longer telomeres, which seems to be a manifestation of all those years of reduced cellular aging in comparison with their more sedentary corresponding participants. It has observed repeatedly that levels of physical activity or exercise are related to longer telomere lengths in different populations whereby athletes are found to express longer telomere lengths than those shown by non-athletes example Arsenis et al. [33], and underlining the unique influence of exercise in contesting the typical age-induced and disease-induced diminutions of telomere length Edwards et al. [34]; Muniesa et al. [35].

In conclusion, it is become a critical postulate in the search for health and well-being that individuals must be active, exercise and eat selectively if they may be recipient of longevity and relative resilience to illness. Nevertheless, it must be borne in mind that the manifest benefit of exercise, confirmed for a large number of neuropsychiatric and neurologic conditions, may not be unrestrictedly the intervention of choice over all possible health constraints.

\section{References}

1. Hitchings R, Latham A (2017) Exercise and environment: New qualitative work to link popular practice and public health. Health Place S1353-8292: 3036930376.

2. Lauer EE, Jackson AW, Martin SB, Morrow JR (2017) meeting usdhhs physical activity guidelines and health outcomes. Int J Exerc Sci 10: 121-127.

3. Duberg A, Möller M, Sunvisson H (2016) I feel free: Experiences of a dance intervention for adolescent girls with internalizing problems. Int $\mathrm{J}$ Qual Stud Health Well-being 11: 31946

4. Schmidt L, Rempel G, Murray TC, McHugh TL, Vallance JK (2016) Exploring beliefs around physical activity among older adults in rural Canada. Int J Qual Stud Health Well-being 11: 32914

5. Sylvester BD, Lubans DR, Eather N, Standage M, Wolf SA, et al. (2016) Effects of variety support on exercise-related well-being. Appl Psychol Health Well Being 8: 213-31.

6. Ruegsegger GN, Booth FW (2017) Health benefits of exercise. Cold Spring Harb Perspect Med.

7. Hattar A, Pal S, Hagger MS (2016) Predicting physical activity-related outcomes in overweight and obese adults: A health action process approach. Appl Psychol Health Well Being 8: 27-51.

8. Langguth N, Schmid J, Gawrilow C, Stadler G (2016) Within-person link between depressed affect and moderate-to-vigorous physical activity in adolescence: An intensive longitudinal approach. Appl Psychol Health Well Being 8: 44-63.

9. Ross SE, Francis LA (2016) Physical activity perceptions, context, barriers, and facilitators from a Hispanic child's perspective. Int J Qual Stud Health Wellbeing 11: 31949 .

10. Luongo TS, Lambert JP, Gross P, Nwokedi M, Lombardi AA, et al. (2017) The mitochondrial $\mathrm{Na}+/ \mathrm{Ca} 2+$ exchanger is essential for $\mathrm{Ca} 2+$ homeostasis and viability. Nature 545: 93-97.

11. Mann TN, Lamberts RP, Nummela A, Lambert MI (2017) Relationship between perceived exertion during exercise and subsequent recovery measurements. Biol Sport 34: 3-9.

12. St Clair Gibson A, Swart J, Tucker R (2017) The interaction of psychological and physiological homeostatic drives and role of general control principles in the regulation of physiological systems, exercise and the fatigue process - The Integrative Governor theory. Eur J Sport Sci, pp: 1-12.

13. Aidar FJ, Jacó de Oliveira R, Gama de Matos D, Chilibeck PD, de Souza RF, et al. (2017) A randomized trial of the effects of an aquatic exercise program on depression, anxiety levels, and functional capacity in of people who suffered an ischemic stroke. J Sports Med Phys Fitness.

14. Holmquist S, Mattsson S, Schele I, Nordström P, Nordström A (2017) Low physical activity as a key differentiating factor in the potential high-risk profile for depressive symptoms in older adults. Depress Anxiety.

15. Pelletier L, Shanmugasegaram S, Patten SB, Demers A (2017) Selfmanagement of mood and/or anxiety disorders through physical activity/ exercise. Health Promot Chronic Dis Prev Can 37: 149-159.

16. Sui X, Ott J, Becofsky K, Lavie CJ, Ernstsen L, et al. (2017) Cardiorespiratory fitness and all-cause mortality in men with emotional distress. Mayo Clin Proc.

17. Dunsky A, Abu-Rukun M, Tsuk S, Dwolatzky T, Carasso R, et al. (2017) The effects of a resistance vs. an aerobic single session on attention and executive functioning in adults.

18. Ji L, Zhang H, Potter GG, Zang YF, Steffens DC, et al. (2017) Multiple neuroimaging measures for examining exercise-induced neuroplasticity in older adults: A quasi-experimental study front aging. Neurosci 9: 102.

19. Northey JM, Cherbuin N, Pumpa KL, Smee DJ, Rattray B (2017) Exercise interventions for cognitive function in adults older than 50 : A systematic review with meta-analysis. Br J Sports Med.

20. Engberg E, Tikkanen HO, Koponen A, Hägglund H, Kukkonen-Harjula K, et al (2017) Cardiorespiratory fitness and health-related quality of life in women at risk for gestational diabetes. Scand J Med Sci Sports.

21. Mastrorilli V, Scopa C, Saraulli D, Costanzi M, Scardigli R, et al. (2017) Physical exercise rescues defective neural stem cells and neurogenesis in the adult subventricular zone of Btg1 knockout mice. Brain Struct Funct.

22. King JA, Deighton K, Broom DR, Wasse LK, Douglas JA, et al. (2017) Individual variation in hunger, energy intake, and ghrelin responses to acute exercise. Med Sci Sports Exerc 49: 1219-1228.

23. Magobe NBD, Poggenpoel M, Myburgh C (2017) Experiences of patients with hypertension at primary health care in facilitating own lifestyle change of regular physical exercise. Curationis 40: e1-e8.

24. Cobley JN, Close GL, Bailey DM, Davison GW (2017) Exercise redox biochemistry: Conceptual, methodological and technical recommendations. Redox Biol 12: 540-548.

25. Liao CF, Yang TY, Chen YH, Yao CH, Way TD, et al. (2017) Effects of swimming exercise on nerve regeneration in a rat sciatic nerve transection model. Biomedicine (Taipei) 7: 3 .

26. Theisen CC, Sachdeva R, Austin S, Kulich D, Kranz V et al. (2017) Exercise and peripheral nerve grafts as a strategy to promote regeneration after acute or chronic spinal cord injury. J Neurotrauma 34: 1909-1914.

27. Zanuso S, Sacchetti M, Sundberg CJ, Orlando G, Benvenuti P, et al. (2017) Exercise in type 2 diabetes: genetic, metabolic and neuromuscular adaptations: A review of the evidence. $\mathrm{Br} \mathrm{J}$ Sports Med.

28. Brown BM, Sohrabi HR, Taddei K, Gardener SL, Rainey-Smith SR, et al (2017) Habitual exercise levels are associated with cerebral amyloid load in presymptomatic autosomal dominant Alzheimer's disease. Alzheimers Dement

29. Pasanen T, Tolvanen S, Heinonen A, Kujala UM (2017) Exercise therapy for functional capacity in chronic diseases: An overview of meta-analyses of randomised controlled trials. $\mathrm{Br} \mathrm{J}$ Sports Med.

30. Chatterjee S (2017) Telomeres in health and disease. J Oral Maxillofac Patho 21: 87-91.

31. Mons U, Müezzinler A, Schöttker B, Dieffenbach AK, Butterbach K, et al. (2017) Leukocyte telomere length and all-cause, cardiovascular disease, and cancer mortality: Results from individual-participant-data meta-analysis of 2 large prospective cohort studies. Am J Epidemiol, pp: 1-10.

32. Solomon Z, Tsur N, Levin Y, Uziel O, Lahav M, et al. (2017) The implications of war captivity and long-term psychopathology trajectories for telomere length. Psychoneuroendocrinology 81: 122-128.

33. Arsenis NC, You T, Ogawa EF, Tinsley GM, Zuo L (2017) Physical activity and telomere length: Impact of aging and potential mechanisms of action. Oncotarget.

34. Edwards MK, Loprinzi PD (2017) Sedentary behavior, physical activity and cardiorespiratory fitness on leukocyte telomere length. Health Promot Perspect 7: 22-27.

35. Muniesa CA, Verde Z, Diaz-Ureña G, Santiago C, Gutiérrez F, et al. (2016) Telomere length in elite athletes. Int J Sports Physiol Perform, pp: 1-13. 